\title{
Article \\ Expiration-Day Effects of Index Futures in a Frontier Market: The Case of Ho Chi Minh Stock Exchange
}

\author{
Anh Thi Kim Nguyen ${ }^{1}$, Loc Dong Truong ${ }^{2, *(1)}$ and H. Swint Friday ${ }^{3}$ \\ 1 Faculty of Economics and Business Administration, An Giang University, Vietnam National University Ho \\ Chi Minh City, Long Xuyen 90116, Vietnam; ntkanh@agu.edu.vn \\ 2 College of Economics, Can Tho University, Can Tho 94115, Vietnam \\ 3 RELLIS Campus, Texas A\&M University, Bryan, TX 77807, USA; swint.friday@tamucc.edu \\ * Correspondence: tdloc@ctu.edu.vn
}

Citation: Nguyen, Anh Thi Kim, Loc Dong Truong, and H. Swint Friday. 2022. Expiration-Day Effects of Index Futures in a Frontier Market: The Case of Ho Chi Minh Stock Exchange. International Journal of Financial Studies 10: 3. https://doi.org/ $10.3390 / \mathrm{ijfs} 10010003$

Received: 25 October 2021 Accepted: 2 December 2021 Published: 29 December 2021

Publisher's Note: MDPI stays neutral with regard to jurisdictional claims in published maps and institutional affiliations.

Copyright: () 2021 by the authors. Licensee MDPI, Basel, Switzerland. This article is an open access article distributed under the terms and conditions of the Creative Commons Attribution (CC BY) license (https:// creativecommons.org/licenses/by/ $4.0 /)$.

\begin{abstract}
This study employs OLS, GARCH and EGARCH regression models to test the expirationday effects of index stock futures on market returns, volatility and trading volume for the Ho Chi Minh Stock Exchange (HOSE). Data used in this study is from a daily return series of the VN30-Index for the period from 10August 2017 through 30 June 2020. The results derived from GARCH $(1,1)$ and EGARCH $(1,1)$ models consistently confirm that Index futures expiration-day effects on market returns exists in the HOSE. Specifically, the average market return for expiration days is significantly lower than other trading days, by $0.13 \%$ at the $5 \%$ level of significance. However, the results obtained from the regression models indicate that the expiration-day has no impact on market volatility and trading volume.
\end{abstract}

Keywords: index futures expiration-day effects; market returns; market volatility; trading volume; HOSE

\section{Introduction}

Black Monday, 19 October 1987 sent shockwaves through global markets and first informed the average investor about the potentially tenuous relationship between index futures contracts and the underlying bundle of stocks that compose the index. At their introduction in the early 1980s, index futures contracts met the needs of a wide variety of market participants seeking to mitigate market risk and provided the prospect of major trading profits that attracted legendary market players like Bear Stearns and Salomon Brothers. Since that time, stock index futures have continued to garner ever increasing attention from academics, regulatory agencies and especially risk averse return optimizing investors across the globe. Some of the key issues examined by these varied groups are trading activities and opportunities that surround the expiration-day for these futures contracts, and the effects that this date possibly has on the underlying bundle of stocks that composes the market index.

Expiration-day effects refer to the abnormal movements of spot market prices, volatility and trading volume around the settlement day. Stoll and Whaley (1997) identified four potential sources that drive expiration day effects. First is arbitrage trading where traders take advantage of profitable differences between the value of the underlying basket of stocks and the index futures. The use of cash settlement for the contracts is another reason if arbitragers unwind positions simultaneously in the same direction. The third source is market procedures to account for order imbalances as the close approaches. The last potential cause is outright manipulation. This can be either direct or indirect manipulation. Direct is self-explanatory in that a participant attempts to influence one side of the settlement equation for ill-gotten gains. Indirect is a little more nuanced in that in this case a trader may unwind an arbitrage position in a way that moves stock prices within the bundle to benefit a pending trade in another account. 
Many studies have examined the existence of the expiration-day effects for a multitude of global markets. However, results from these studies have been mixed. Some studies found that the market returns and trading volume for expiration days are significantly higher than other days (Chamberlain et al. 1989; Stoll and Whaley 1997; Alkebäck and Hagelin 2004; Chen et al. 2011; Sadath and Kamaiah 2011; Batrinca et al. 2020) while other studies found negative expiration-day effects on market returns (Stoll and Whaley 1987; Alkebäck and Hagelin 2004; Chow et al. 2003). In addition, the expiration-day effects on spot market volatility have been detected in many studies (Stoll and Whaley 1987; Chamberlain et al. 1989; Alkebäck and Hagelin 2004; Chen et al. 2011). However, other studies reported that the expiration-day effect on stock market volatility is not present for some markets (Bollen and Whaley 1999; Kan 2001).

This study investigates the impact of the index futures expiration-day on spot market returns, volatility and trading volume for the HOSE. The Vietnam derivatives market was officially launched on 10 August 2017 with the initial offering of the VN30-Index futures contract. Since this introduction, the market has substantially grown to a market capitalization that exceeds USD 200 billion at the end of 2020 and attracts ever-increasing attention from global investors (Truong and Friday 2021). According to the 2020 annual report of HOSE, at the end of 2020 there were 31,134 foreign individuals and 3937 foreign organizations investing in the Vietnam stock market, amounting to a $16.7 \%$ year-over-year increase. As the market continues to mature and attract more international attention, the VN30-Index futures contract should see rapid growth from both domestic and international investors in the coming years. Especially, after Kuwait graduated to Morgan Stanley Capital International (MSCI) Emerging Market status, Vietnam became the largest component of the MSCI Frontier Markets index with a weighting of just over 30\%, leading additional international inflows as frontier market funds rebalanced ${ }^{1}$. This study contributes to the literature on financial derivative markets in developing frontier markets by providing the first empirical findings of index futures expiration-day effects in Vietnam's HOSE. The HOSE provides an excellent case for studying expiration-day effects. First, the HOSE is one of only a few frontier stock markets that have launched a derivatives market. Second, the derivatives market has operated only for a short period and the individual investors have dominated market trading. For this reason, the expiration-day effects are expected to be more pronounced on the HOSE. Moreover, it is expected that the empirical evidence derived from this study will be useful information for Vietnamese policy makers to assess current regulations and implement new ones to enhance market growth and development in the future.

The hypotheses of this study are that (1) the market returns on expiration days are lower than on other trading days; (2) the market volatility on expiration days is higher than on other trading days; and (3) the market trading volume on expiration days is higher than on other trading days. These hypotheses are tested by using GARCH and EGARCH models. The results derived from the regression models reveal that the average market return for expiration days is lower than that of other trading days by $0.13 \%$ at the $5 \%$ level of significance. However, the index futures expiration-day has no impact on market volatility and trading volume.

The remainder of the paper is organized as follows. Section 2 provides background on the new Vietnam stock index futures contract. Section 3 reviews the empirical literature. Section 4 describes the data used in the study as well as the research methodology. Section 5 discusses the empirical results. Finally, Section 6 provides conclusions.

\section{Overview of Vietnam Stock Index Futures}

Vietnam is new entrant to both the world's stock market fraternity and to the introduction of market index futures. Established on 28 July 2000, the HOSE is the first and largest stock exchange in Vietnam. At the end of June 2020, a total of 380 companies with a total market capitalization of VND 2,874,204 billion (about USD 124.48 billion) traded on the Exchange. Just a few years ago, the Vietnam derivatives market was officially 
launched on 10 August 2017 with the introduction of the VN30-Index futures contract, a market capitalization weighted index of 30 large capitalization and high liquidity stocks traded on HOSE. This new derivative contract has been well received as measured by its ever-increasing trading volume, and according to statistics provided by the Ha Noi Stock Exchange, average daily trading volume has risen from 10,954 contracts in 2017 to a very respectable 164,631 contracts in the first half of 2020. Especially, Truong and Friday (2021) asserted that the introduction of index futures contract facilitates market efficiency by providing investors with a more cost-effective means to arbitrage away the daily returns anomaly.

By regulation, the index futures contract expires on the third Thursday of each month. In addition, the Vietnam derivatives market employs a cash settlement process based on the closing price of the underlying market on the expiration day as the settlement price for the index futures contract. This creates the possibility that trading volume could move stock prices around the expiration date if many arbitrageurs liquidate their position in the same direction. However, based on our review of the literature, no study has analyzed this issue for the HOSE. Table 1 below provides the contract specifications for the VN-30 Index futures contract.

Table 1. Contract specification for the VN30-Index Futures.

\begin{tabular}{cc}
\hline Characteristics & Regulations \\
\hline Underlying asset & VN30-Index \\
\hline Contract size & VND 100,000 $\times$ VN30-Index point \\
\hline Multiplier & Current month, the next month and the last month of the next \\
two quarters
\end{tabular}

As presented in Table 1, the VN30-Index has been selected as the underlying asset for the index futures contracts in Vietnam. According to Nguyen and Truong (2020), the index futures contract based on the VN30-Index is less risky than individual stocks' future. At a certain time, four different kinds of index futures contracts with different maturity months are traded in the market. Maturity months of the VN30-Index futures contracts are the current month, the next month and the last month of the next two quarters. Like other markets, investors need to post a certain amount of cash, known as the initial margin requirement and additional margin, when necessary, based on the results of their trading. The initial margin rate that is set by the Securities Depository Center is currently $10 \%$. The Index futures contracts have a trading collar which is determined for each specific contract within the range of the ceiling price and the floor price. The trading collar of theVN30-Index futures is currently $7 \%$. 


\section{Literature Review}

The expiration-day effects on underlying stock market returns and volatility have been widely studied in the financial literature around the world for several decades. Stoll and Whaley (1987) were among the first to research these effects in North American markets. They investigated the expiration-day effects of US markets for the period from 1983 to 1985 . They found that stock prices tend to fall around derivatives' settlement dates. Chamberlain et al. (1989) examined the index futures and options expiration-day effects for the Toronto stock exchange. Findings from this study confirmed that the mean return for expiration days is significantly higher than that of other days.

For European markets, Alkebäck and Hagelin (2004) investigated the index futures and options expiration-day effects on the Swedish market during the period from 1988 to 1998. They found that the expiration-day effects on market returns are not present for the entire sample. However, the market returns of expiration weeks are lower than in other weeks for the sub-period of 1988-1991. The index futures and options expiration-day effects on the Swedish market after a change of expiration day were also examined by $\mathrm{Xu}$ (2014). This study did not find any significant impact of the expiration day on market returns. In Asia, Chow et al. (2003) measured the effect of the expiration of Hang Seng Index derivatives on the underlying market returns in Hong Kong during the period from 1990 to 1999 . The authors reported that the average of underlying market returns on the expiration days is lower than that of other comparison days. In addition, Chen et al. (2011) tested for the impact of the expiration-day in the Taiwan futures exchange over the period from 1998 to 2009 . The empirical results derived from the study revealed that the market returns on expiration days are significantly higher than on non-expiration days. Sadath and Kamaiah (2011) measured the effects of individual stock futures expiration on the underlying stock market in the Indian stock market. This study found positive expiration-day effects on stock returns.

Another aspect that has received increased attention from researchers is the expirationday effect of index futures on spot market volatility. Bollen and Whaley (1999) argued that the selection of index derivatives settlement price could cause market volatility. If the settlement price is based on the prices of the underlying index at a single point in time (the closing or opening) on the expiration-day, arbitrageurs could liquidate their positions at the same time causing abnormal trading activity to occur and possibly creating abnormal stock market volatility. However, some stock exchanges use average prices as the settlement prices for index derivatives. This policy encourages index arbitrageurs to liquidate their positions uniformly throughout the last trading day, thereby making their liquidation demand less concentrated and mitigating the market volatility induced by order imbalances.

Many studies have found that the volatility of spot market returns on expiration days is significantly higher than on other trading days. Stoll and Whaley (1987) found significant increase in volatility on expiration days for the US market. Similarly, Chamberlain et al. (1989) documented that the volatility of market returns on expiration days is significantly higher than that of other days for the Toronto stock exchange. In addition, Park and Lim (2003) examine the impact of the expiration of KOSPI 200 derivatives on the underlying cash market in the Korea stock exchange. Using daily data for the period from 1997 to 2002, findings from this study confirmed that the market returns and volatility in the last 10 min on expiration days is significantly greater than on other days. In addition, Alkebäck and Hagelin (2004) confirmed that the market volatility on expiration days is significantly greater than on non-expiration days for the Swedish market. The same finding was also found by Chen et al. (2011) for the Taiwan futures exchange. Moreover, Chow et al. (2003) pointed out that the market volatility on expiration days is significantly higher than that of one and five trading days before the expiration day for the Hong Kong market. On the contrary, Bollen and Whaley (1999) and Kan (2001) found that expiration-day effects on stock market volatility were not observed for the Hong Kong Stock Exchange. Similarly, Debasish (2010) found no evidence of the Nifty index futures expiration-day effects on 
stock market returns and volatility. In a recent study, Samineni et al. (2020) examined the expiration-day effects of Nifty Bank index derivative contracts on underlying market returns and volatility for the period 2010-2020 in India. Using the EGARCH(1,1) model, the empirical results revealed that there are no expiration-day effects on the returns and volatility of the underlying index.

Moreover, some studies have examined the impact of the derivatives expiration-day on underlying market liquidity. However, the empirical results drawn from these studies are inconsistent. Specifically, Stoll and Whaley (1997); Alkebäck and Hagelin (2004); Debasish (2010); Batrinca et al. (2020) and Gurgul and Suliga (2020) found that trading volume on expiration-day is higher than on other trading days. Furthermore, Park and Lim (2003) documented the expiration-day effects of index futures and options on trading volume by using observations during the last $60 \mathrm{~min}$ of trading for the Korea stock exchange. In contrast, the evidence obtained from Chamberlain et al. (1989) and Bollen and Whaley (1999) pointed out that expiration-day volume effects do not occur, supporting the view that derivatives trading does not disrupt the underlying market.

Overall, this research indicates that expiration-day effects of derivatives on underlying stock returns, volatility and trading volume have been found in many markets. Empirical evidence of the expiration-day effect on spot market returns has been mixed. Some studies have confirmed that the market return for expiration days is significantly higher than other days while some evidence has been found that the market return on the expiration days is lower than on non-expiration days. Regarding the expiration-day effects on spot market volatility and trading volume, most studies asserted that the market trading volume and the volatility of market returns on expiration days is significantly higher than that of other trading days. However, other studies have reported that the expiration-day of derivatives does not have a measurable effect on underlying stock market volatility and trading volume for other markets.

\section{Data and Methodology}

The data employed in this study consist of daily VN30-Index and market returns and trading volume series. The data are collected for the period from 10 August 2017 through 30 June 2020 from the website of the HOSE (https:/ / www.hsx.vn/, accessed on 30 July 2020). Then, a natural logarithmic transformation is conducted for the primary data to generate a time series of continuously compounded returns. Specifically, the spot market returns are calculated by the following equation:

$$
R_{t}=\log \left(P_{t}\right)-\log \left(P_{t-1}\right)
$$

where

$R_{t}$ : Market returns on trading day $t ;$

$P_{t}:$ VN30-Index at the end of trading day $t$;

$P_{t-1}:$ VN30-Index at the end of trading day $t-1$.

The descriptive statistics fir the daily market returns and trading volume for the sample are shown in Table 2. The average daily return for the entire sample for the period is 0.000023 . This is low compared to the standard deviation of daily returns for the entire sample of 0.005459 . In addition, the average daily return for the expiration days is negative at -0.001204 making it lower than other trading days from the sample period. Specifically, the market declined on average by $0.12 \%$ on the expiration days while it was on average higher by $0.01 \%$ on other trading days than the entire sample mean. The range of daily returns for the expiration day sample at $0.027792 \%$ is half the size of the non-expiration day daily returns range of $0.050365 \%$. What is really telling is an examination of the coefficient of variation $(\mathrm{CoV})$ for the different samples. The $\mathrm{CoV}$ for the non-expiration day subset is 62.92. However, it is only -5.21 for the expiration day subset. This indicates that though the standard deviation of the observed daily returns is slightly higher for the expiration day returns, it is relatively much lower than the average returns for the non-expiration 
days. In addition, when the negative returns for the expiration day subset are included in the average for the entire sample, the CoV explodes to 237.35.

Table 2. Daily returns and summary statistics of the sample.

\begin{tabular}{|c|c|c|c|c|c|c|}
\hline & Observations & Minimum & Maximum & Mean & $\begin{array}{c}\text { Standard } \\
\text { Deviation }\end{array}$ & $\begin{array}{c}\text { Coefficient of } \\
\text { Variation }\end{array}$ \\
\hline \multicolumn{7}{|c|}{ 1. Daily returns } \\
\hline Expiration days & 35 & -0.019754 & 0.008038 & -0.001204 & 0.006278 & -5.21 \\
\hline Other days & 685 & -0.028512 & 0.021853 & 0.000086 & 0.005411 & 62.92 \\
\hline Entire sample & 720 & -0.028512 & 0.021853 & 0.000023 & 0.005459 & 237.35 \\
\hline \multicolumn{7}{|c|}{ 2. Daily trading volume } \\
\hline Expiration days & 35 & $30,312,030$ & $134,973,200$ & $57,818,706$ & $20,534,990$ & 0.36 \\
\hline Other days & 685 & $14,686,540$ & $191,851,870$ & $58,928,213$ & $24,944,196$ & 0.42 \\
\hline Entire sample & 720 & $14,686,540$ & $191,851,870$ & $58,874,279$ & $24,737,058$ & 0.42 \\
\hline
\end{tabular}

This table summarizes descriptive statistics of daily market returns and trading volume for the entire sample and index futures expiration days during the period from 10 August 2017 to 30 June 2020.

In addition, Table 2 shows that the average daily trading volume for the entire sample is $58,874,279$ shares with the standard deviation of $24,737,058$ shares. The average daily trading volume on index futures expiration days is lightly lower than non-expiration days. Specifically, the average market trading volume is $57,818,706$ shares on the expiration days while other days reach an average trading volume of 58,928,213 shares. Interestingly, the range of trading volume on expiration days is much lower at just over 100 million shares when compared to non-expiration days at over 177 million.

To investigate the effects of index futures expiration days on spot market returns and volatility, OLS (ordinary least squares) regression is used in this study. Specifically, the model takes the following equation:

$$
R_{t}=\alpha_{0}+\alpha_{1} D_{E t}+\alpha_{2} D_{1 t}+\alpha_{3} D_{2 t}+\alpha_{4} D_{3 t}+\alpha_{5} D_{4 t}+\varepsilon_{t}
$$

where $R_{t}$ is underlying market returns on trading day $t ; D_{E t}$ is a dummy variable for index futures expiration days, equal to 1 if observation $t$ occurs on the index futures expiration days and 0 otherwise; $D_{1}, D_{2}, D_{3}, D_{4}$ are dummy variables for Monday, Tuesday, Wednesday and Friday, respectively (i.e., $D_{1 t}$ equal 1 if observation $t$ is on Monday and 0 otherwise). The dummy variables for days of the week are employed as control variables for the day-of-the week effect that can be present in the stock market.

It is important to note that the OLS model assumes that the variance of the errors is constant over time (homoscedasticity). However, this assumption is often violated in stock returns series where heteroskedasticity is often observed. Moreover, if the assumption of homoscedasticity is not fulfilled and the OLS model is applied, the standard errors could be mis-specified and any conclusions drawn from the model misleading (Brooks 2002). To address this issue, the GARCH(p,q) model which was developed by Engle (1982) and Bollerslev (1986) is used in this study to account for any ARCH (autoregressive conditional heteroscedasticity) effects that possibly exist in the studied model. Based on the Akaike information criterion (AIC), the most appropriate model is selected (the model has the lowest AIC value) to arrive at the conclusion of the study. The GARCH(p,q) employed in this study takes the form as follows:

$$
\begin{aligned}
& R_{t}=\alpha_{0}+\alpha_{1} D_{E t}+\alpha_{2} D_{1 t}+\alpha_{3} D_{2 t}+\alpha_{4} D_{3 t}+\alpha_{5} D_{4 t}+\varepsilon_{t} \varepsilon_{t} \approx N\left(0, h_{t}\right) \\
& h_{t}=\omega+\sum_{i=1}^{p} \beta_{i} \varepsilon_{t-i}^{2}+\sum_{j=1}^{q} \delta_{j} h_{t-j}
\end{aligned}
$$

Furthermore, the standard GARCH models are based on the assumption that timevarying conditional volatility is symmetric. However, effects of information on the volatility of stock returns are usually asymmetric. In fact, bad news often leads to volatility of stock 
returns more than good news (Kim et al. 2004; Spyrou 2005). To address this issue, Nelson (1991) developed the EGARCH model that takes into account the leverage effects in a timeseries. Therefore, we also employ the $\operatorname{EGARCH}(p, q)$ model in this study as a robustness check for the effects of index futures expiration-day on underlying market returns. The EGARCH(p,q) model is also used in order to test for the effect of index futures expiration-day on the volatility of underlying market returns in the Vietnam stock market. Specifically, the $\operatorname{EGARCH}(\mathrm{p}, \mathrm{q})$ is given by the following equations:

$$
\begin{aligned}
& R_{t}=\alpha_{0}+\alpha_{1} D_{E t}+\alpha_{2} D_{1 t}+\alpha_{3} D_{2 t}+\alpha_{4} D_{3 t}+\alpha_{5} D_{4 t}+\varepsilon_{t} \varepsilon_{t} \approx N\left(0, \sigma_{t}^{2}\right) \\
& \ln \left(\sigma_{t}^{2}\right)=\beta_{0}+\sum_{i=1}^{q} \delta_{i} \ln \left(\sigma_{t-i}^{2}\right)+\gamma \frac{\varepsilon_{t-1}}{\sqrt{\sigma_{t-1}^{2}}}+\sum_{j=1}^{p} \beta_{j}\left[\frac{\left|\varepsilon_{t-1}\right|}{\sqrt{\sigma_{t-1}^{2}}}-\sqrt{\frac{2}{\pi}}\right]+\varphi D_{E t}
\end{aligned}
$$

where $\delta_{i}$ and $\beta_{j}$ are coefficients of GARCH and ARCH effects respectively. In addition, with the assumption of $\varepsilon_{t} \approx N\left(0, \sigma_{t}^{2}\right)$, the $\frac{\varepsilon_{t}}{\sqrt{\sigma_{t}^{2}}}$ variable follows a standard normal distribution and $E\left(\frac{\left|\varepsilon_{t}\right|}{\sqrt{\sigma_{t}^{2}}}=\sqrt{\frac{2}{\pi}}\right)$. The coefficient $\gamma$ captures the leverage effect. For good news $\left(\frac{\varepsilon_{t-1}}{\sqrt{\sigma_{t-1}^{2}}}>\right.$ $0)$, the effect of $\varepsilon_{t-1}$ is $\left(\gamma+\beta_{j}\right) \frac{\varepsilon_{t-1}}{\sqrt{\sigma_{t-1}^{2}}}$ and for bad news $\left(\frac{\varepsilon_{t-1}}{\sqrt{\sigma_{t-1}^{2}}}<0\right)$, the effect is $(-\gamma+$ $\left.\beta_{j}\right) \frac{\varepsilon_{t-1}}{\sqrt{\sigma_{t-1}^{2}}}$. If the asymmetric effects exist, $\gamma$ must be negative (Dhamija and Bhalla 2010).

If the effects of index futures expiration-day on the underlying market returns and volatility exists, $\alpha_{1}$ and $\varphi$ will be non-zero and statistically significant.

Moreover, this study employs the GARCH(1,1) model to examine the effect of index futures expiration-day on trading volume for the HOSE. Specifically, the model is expressed as the following equations:

$$
\begin{aligned}
& \log V_{t}=\omega_{0}+\omega_{1} D_{E t}+\varepsilon_{t} \varepsilon_{t} \approx N\left(0, h_{t}\right) \\
& h_{t}=\omega_{2}+\delta h_{t-1}+\lambda \varepsilon_{t-1}^{2}
\end{aligned}
$$

where $\log V_{t}$ is the natural logarithm of trading volume on trading day $t ; D_{E t}$ is the dummy variable for index futures expiration days, equal to 1 if observation $t$ falls in the index futures expiration days and 0 otherwise.

\section{Empirical Results}

5.1. The Effects of Index Futures Contract Expiration-Day on Spot Market Returns and Volatility

As presented in Section 4, this study employs a set of regression models to estimate the effects of the index futures expiration-day on the market returns. In order to select the appropriate $\operatorname{GARCH}(p, q)$ and $\operatorname{EGARCH}(p, q)$ models, we perform several models $(p=1$, $2,3 ; q=1,2)$. Based on the AIC, we find that the $\operatorname{GARCH}(1,1)$ and $\operatorname{EGARCH}(1,1)$ are the most appropriate models to measure the effects of index futures contract expiration-day on market returns and volatility for the HOSE. The results obtained from OLS, GARCH $(1,1)$ and EGARCH $(1,1)$ regression models are summarized in Table 3. The main findings drawn from the OLS model indicate that the expiration-day effect of index futures contracts on market returns is not present in the HOSE. However, this conclusion does not take into account the ARCH effect that is suspected to be present in the model. To test for the existence of ARCH effects, the Lagrange Multiplier approach, developed by Engle (1982), is employed. The results of the ARCH-LM test presented in Table 3 provide solid confirmation that ARCH effects exist in the OLS model because the test statistic of the model is higher than the LM-critical value at the $1 \%$ significance level. Due to ARCH effects in the model, the GARCH $(1,1)$ and $\mathrm{EGARCH}(1,1)$ models are more appropriate than the OLS model in testing for the impact of index futures expiration-day on market daily returns. 
Table 3. The effects of index futures expiration-day on market returns and volatility.

\begin{tabular}{|c|c|c|c|}
\hline Variable & OLS & GARCH $(\mathbf{1}, \mathbf{1})$ & EGARCH $(1,1)$ \\
\hline \multicolumn{4}{|c|}{ Conditional mean equation } \\
\hline$\alpha_{0}$ (constant) & $\begin{array}{c}-0.00082 \\
(-1.63)\end{array}$ & $\begin{array}{l}-0.0001 \\
(-0.40)\end{array}$ & $\begin{array}{c}-0.00018 \\
(-0.47)\end{array}$ \\
\hline $\begin{array}{l}\alpha_{1} \text { (Index futures } \\
\text { expiration-day) }\end{array}$ & $\begin{array}{c}-0.00045 \\
(-0.43)\end{array}$ & $\begin{array}{l}-0.00114 \\
(-1.81) *\end{array}$ & $\begin{array}{l}-0.00134 \\
(-1.99)^{* *}\end{array}$ \\
\hline$\alpha_{2}$ (Monday) & $\begin{array}{c}0.00047 \\
(0.68)\end{array}$ & $\begin{array}{c}0.00004 \\
(0.10)\end{array}$ & $\begin{array}{c}-0.00005 \\
(-0.10)\end{array}$ \\
\hline$\alpha_{3}$ (Tuesday) & $\begin{array}{c}0.00079 \\
(1.17)\end{array}$ & $\begin{array}{c}0.00006 \\
(0.11)\end{array}$ & $\begin{array}{c}0.00008 \\
(0.15)\end{array}$ \\
\hline$\alpha_{4}$ (Wednesday) & $\begin{array}{l}0.00141 \\
(2.12) * *\end{array}$ & $\begin{array}{l}0.00085 \\
(1.70) *\end{array}$ & $\begin{array}{c}0.00063 \\
(1.23)\end{array}$ \\
\hline$\alpha_{5}$ (Friday) & $\begin{array}{l}0.00162 \\
(2.40)^{* *}\end{array}$ & $\begin{array}{c}0.00104 \\
(1.91)^{*}\end{array}$ & $\begin{array}{c}0.00084 \\
(1.53)\end{array}$ \\
\hline ARCH-LM test (1 lag) & $13.41^{* * *}$ & & \\
\hline \multicolumn{4}{|c|}{ Conditional variance equation } \\
\hline$\beta_{0}$ & & $\begin{array}{c}1.77 \times 10^{-7} \\
(2.03)^{* *}\end{array}$ & $\begin{array}{c}-0.30021 \\
(-4.37)^{* * *}\end{array}$ \\
\hline$\delta_{1}(\mathrm{GARCH}$ effect $)$ & & $\begin{array}{c}0.9306 \\
(98.11)^{* * *}\end{array}$ & $\begin{array}{l}0.98296 \\
(160.47) \\
\end{array}$ \\
\hline$\beta_{1}(\mathrm{ARCH}$ effect $)$ & & $\begin{array}{c}0.0697 \\
(6.39)^{* * * *}\end{array}$ & $\begin{array}{c}0.16509 \\
(6.44)^{* * *}\end{array}$ \\
\hline$\gamma$ (Leverage effect) & & & $\begin{array}{l}-0.04364 \\
(-3.50)^{* * *}\end{array}$ \\
\hline $\begin{array}{l}\varphi \text { (Index futures } \\
\text { expiration-day) }\end{array}$ & & & $\begin{array}{c}0.00888 \\
(0.07)\end{array}$ \\
\hline
\end{tabular}

This table presents the results of OLS, GARCH $(1,1)$ and EGARCH $(1,1)$ models for the index futures expiration-day effect on the underlying market returns and volatility. The lag orders of the models are selected based on AIC.***, ** and ${ }^{*}$ indicate significance at $1 \%, 5 \%$ and $10 \%$ levels, respectively. The numbers in parentheses represent t-values for OLS model and z-values for GARCH(1,1) and EGARCH(1,1) models.

The results derived from the $\mathrm{GARCH}(1,1)$ and $\mathrm{EGARCH}(1,1)$ models also presented in Table 3 consistently indicate that the expiration days of index future contracts have a negative impact on the underlying market returns in Vietnam. Specifically, it is found from the EGARCH $(1,1)$ model that the average market return for expiration days is lower than other trading days by $0.13 \%$ at the $5 \%$ level of significance. This finding is consistent with the conclusions of Chow et al. (2003); Alkebäck and Hagelin (2004) that the futures expiration days have a negative impact on the underlying market returns. It is noted that the Vietnam derivatives market has used the closing market index on expiration days as the price settlement for index futures contracts instead of an average price settlement like other markets. The result of this settlement process may be that investors unwind their short arbitrage positions at the same time on the expiration days, possibly creating imbalances on these days in the HOSE that drive returns into down or even into negative territory. Based on this finding, it is proposed that investors can seek arbitrage opportunities by selling the futures contract (holding a short position) prior to the expiration day and buying the underlying market portfolio at the end of the expiration day.

In order to examine the effect of index futures expiration days on the volatility of market returns, the dummy variable for index futures expiration-day is included in the variance equation of the EGARCH $(1,1)$ model. The results derived from the EGARCH$(1,1)$ model point out that the coefficient of the dummy variable for the index futures expiration days in the conditional variance Equation (4) is positive, but it is not statistically significant. 
Therefore, it is concluded that the index futures expiration day have no impact on the underlying market volatility. This finding is in line with previous findings of Stoll and Whaley (1997); Bollen and Whaley (1999) and Kan (2001) and seems appropriate for the case of Vietnam. The Vietnam derivatives market is in its infancy where products traded in the market are very limited. Therefore, index futures trading activities do not have significant impact on the spot market volatility on expiration days.

In addition, the results derived from the $\operatorname{EGARCH}(1,1)$ reveal that all estimated coefficients for daily dummy variables are not statistically significant at the ten percent level, suggesting that the day-of-the-week effects are not present for the HOSE. It is important to stress that some studies found the presence of the day-of-the-week effect for the HOSE during the pre-index futures period (Truong 2012; Truong and Friday 2021). Therefore, our finding suggests that the introduction of the VN30-Indexfutures contract had an impact on the daily returns anomaly in Vietnam. The disappearance of the daily returns anomaly in the post-index futures period provides evidence that the introduction of index futures contracts lowers the transactions costs of participants and facilitates their arbitrage opportunities to possibly exploit this anomaly more efficiently in the underlying market (Truong and Friday 2021). Furthermore, an asymmetric effect on the market returns volatility is found for the HOSE. Specifically, the results obtained from the EGARCH(1,1) model show that the coefficient of leverage effect is statistically negative at the $1 \%$ level of significance. This result indicates that bad information has a larger effect on the market returns volatility than good information of the same size.

\subsection{The Effect of Index Futures Expiration-Day on Spot Market Trading Volume}

The index futures expiration-day effect is further investigated on the market trading volume. The results derived from the OLS and GARCH $(1,1)$ models are shown in Table 4 . It is found that the index futures expiration-day has no impact on trading volume of the spot market. This result is contrary to previous findings of Stoll and Whaley (1997); Alkebäck and Hagelin (2004); Batrinca et al. (2020) and Gurgul and Suliga (2020). However, these results may reflect the current situation in the Vietnam stock market. According to the statistics provided by the Hanoi stock exchange, investors in the Vietnam derivatives market are mostly individuals. Moreover, the settlement method of the VN30-Index futures is in cash (no transfer of stocks after contract expiration). Therefore, they have used the index futures contract for speculation rather than as a risk management tool for hedging the underlying market. If investors use a futures contract to manage their investment risk, they could combine buying or selling stocks on the spot market to achieve their profit goals on expirations. In this case, the market trading volume should increase. Another possible explanation for the finding is that this study employs the daily market trading volume while the index futures expiration-day effect on trading volume may exist only in the last $15 \mathrm{~min}$ of the trading day. It is noted that the HOSE has applied the periodic order matching method for the last 15 minof the trading day to determine closing price of stocks. As mentioned above, the Vietnam derivatives market has used the closing market index on expiration days as the price settlement for index futures contracts. Therefore, speculators can earn profit from the index-futures contracts by buying or selling certain amount of underlying stocks during the last $15 \mathrm{~min}$ in order to set the stock prices as their goal. 
Table 4. The impact of index futures expiration-day on the spot market trading volume.

\begin{tabular}{|c|c|c|}
\hline Variable & OLS & GARCH $(1,1)$ \\
\hline \multicolumn{3}{|c|}{ Conditional mean equation } \\
\hline$\omega_{0}$ (constant) & $\begin{array}{c}7.7381 \\
(1252.37)^{* * *}\end{array}$ & $\begin{array}{c}7.7154 \\
(212.38)^{* * *}\end{array}$ \\
\hline $\begin{array}{c}\omega_{1} \text { (Index futures } \\
\text { expiration-day) }\end{array}$ & $\begin{array}{c}0.0019 \\
(0.07)\end{array}$ & $\begin{array}{l}0.0001 \\
(0.00)\end{array}$ \\
\hline ARCH-LM test (1 lag) & $254.18^{* * *}$ & \\
\hline \multicolumn{3}{|c|}{ Conditional variance equation } \\
\hline$\omega_{2}$ & & $\begin{array}{c}0.0006 \\
(2.65)^{* * *}\end{array}$ \\
\hline$\lambda(\mathrm{ARCH}$ effect $)$ & & $\begin{array}{c}0.1123 \\
(4.99) * * *\end{array}$ \\
\hline$\delta$ (GARCH effect) & & $\begin{array}{c}0.8325 \\
(21.50)^{* * * *}\end{array}$ \\
\hline
\end{tabular}

This table provides the results of OLS and GARCH(1,1) for the index futures expiration-day effect on the spot market trading volume. ${ }^{* * *}$ indicates significance at $1 \%$. The numbers in parentheses represent $\mathrm{t}$-values for OLS model and z-values for GARCH $(1,1)$.

\section{Conclusions}

This study is devoted to determining the expiration-day effects of the VN30-Index futures contract on the HOSE's underlying spot market returns, volatility and trading volume. The daily series market returns and trading volume of the HOSE covering the period from 10 August 2017 through 30 June 2020 are used for this analysis. Consistent with results presented by Chow et al. (2003) and Alkebäck and Hagelin (2004), the study finds that the spot market returns were on average negative on expiration days for the VN30-Index futures contract and significantly lower than non-expiration trading days which had a positive average daily return. This finding supports the view that arbitrage trading possibly takes place in the HOSE. The Vietnam derivatives market uses the single price settlement and cash settlement for the VN30-Index futures contracts on the expiration day, which may result in the abnormal price effects at expiration days observed in this analysis.

Similar to the findings of Stoll and Whaley (1997); Bollen and Whaley (1999) and Kan (2001), no evidence can be found in this study for the impact of the index futures expirationday on market volatility. In addition, the analysis also finds no significant expiration-day effects on underlying market trading volume. This contradicts results reported by Stoll and Whaley (1997); Alkebäck and Hagelin (2004) and Batrinca et al. (2020) who find a significant impact on underlying market volatility on the expiration day. The authors posit that the lack of impact of expiration-day effects of the VN30-Index futures contract on underlying market volatility and trading volume is due to the Vietnam derivatives market's very early stages in its introduction, with both volume and products traded in the market being limited.

Therefore, the authors conclude that the regulations on the settlement price of futures expiration-day may continue to be applied in the future because this regulation can reduce the speculation of individual investors, thereby reducing market volatility on expirationdays in Vietnam. When considering all the results together, it can be concluded that investors potentially can earn abnormal returns by using arbitrage strategies in the Vietnam stock market using the VN30-Index futures contract. In order to develop the derivatives market stably, the State Security Commission of Vietnam should implement policies to attract more institutional investors and reduce transaction costs.

Although this study has made a contribution to the literature, it still has a limitation which should be addressed in future empirical research. It is noted that the HOSE has applied periodical order matching method for the last $15 \mathrm{~min}$ to determine the closing price 
of stocks. In addition, the Vietnam derivatives market uses the closing price settlement for the VN30-Index futures contracts on the expiration day. Therefore, trading volume and prices of stocks may fluctuate highly in the last $15 \mathrm{~min}$ of the expiration-day. However, we cannot obtain data of stock prices and trading volumes for the last 15 min of each market trading day. This limitation awaits further research.

Author Contributions: Conceptualization, A.T.K.N., L.D.T. and H.S.F.; methodology, L.D.T. and A.T.K.N.; software, L.D.T. and A.T.K.N.; validation, L.D.T.; formal analysis, A.T.K.N., L.D.T. and H.S.F.; investigation, L.D.T.; resources, A.T.K.N.; data curation, L.D.T. and A.T.K.N.; writing-original draft preparation, A.T.K.N. and L.D.T.; writing-review and editing, H.S.F., L.D.T. and A.T.K.N.; visualization, L.D.T. and H.S.F.; project administration, L.D.T. All authors have read and agreed to the published version of the manuscript.

Funding: This research received no external funding.

Data Availability Statement: The data that support the findings of this research are available from the corresponding author upon request.

Conflicts of Interest: The authors declare no conflict of interest.

\section{Notes}

1 See Arouri et al. (2013) for more detail on related research in emerging markets.

\section{References}

Alkebäck, Per, and Niclas Hagelin. 2004. Expiration day effects of index futures and options: Evidence from a market with a long settlement period. Applied Financial Economics 14: 385-96. [CrossRef]

Arouri, Mohamed El Hedi, Sabri Boubaker, and Duc Khuong Nguyen, eds. 2013. Emerging Markets and the Global Economy: A Handbook. Cambridge, MA: Academic Press.

Batrinca, Bogdan, Christian W. Hesse, and Philip C. Treleaven. 2020. Expiration day effects on European trading volumes. Empirical Economics 58: 1603-38. [CrossRef]

Bollen, Nicolas P. B., and Robert E. Whaley. 1999. Do expirations of Hang Seng Index derivatives affect stock market volatility? Pacific-Basin Finance Journal 7: 453-70. [CrossRef]

Bollerslev, Tim. 1986. Generalized autoregressive conditional heteroskedasticity. Journal of Econometrics 31: 307-27. [CrossRef]

Brooks, Chris. 2002. Introductory Econometrics for Finance. New York: Cambridge University Press.

Chamberlain, Trevor W., C. Sherman Cheung, and Clarence C. Y. Kwan. 1989. Expiration-day effects of index futures and options: Some Canadian evidence. Financial Analysts Journal 45: 67-71. [CrossRef]

Chen, Chia Cheng, Su-Wen Kuo, and Chin-Sheng Huang. 2011. Expiration-day effects, settlement mechanism, and market structure: An empirical examination of Taiwan futures exchange. Investment Management and Financial Innovations 8: 80-87.

Chow, Ying-Foon, Haynes H. M. Yung, and Hua Zhang. 2003. Expiration day effects: The case of Hong Kong. Journal of Futures Markets 23: 67-86. [CrossRef]

Debasish, Sathya Swaroop. 2010. Investigating expiration day effects in stock index futures in India. Journal of Economics and Behavioral Studies 1: 9-19. [CrossRef]

Dhamija, Ajay K., and Vinod K. Bhalla. 2010. Financial time series forecasting: Comparison of neural networks and ARCH models. International Research Journal of Finance and Economics 49: 194-212.

Engle, Robert F. 1982. Autoregressive conditional heteroscedasticity with estimates of the variance of United Kingdom inflation. Econometric 50: 987-1007. [CrossRef]

Gurgul, Henryk, and Milena Suliga. 2020. Impact of futures expiration on underlying stocks: Intraday analysis for Warsaw Stock Ex-change. Central European Journal of Operations Research 28: 869-904. [CrossRef]

Kan, Andy C. N. 2001. Expiration-day effect: Evidence from high-frequency data in the Hong Kong stock market. Applied Financial Economics 11: 107-18. [CrossRef]

Kim, Minho, GyeongRok Kim, and Mincheol Kim. 2004. Stock market volatility and trading activities in the KOSPI 200 derivatives markets. Applied Economics Letters 11: 49-53. [CrossRef]

Nelson, Daniel B. 1991. Conditional heteroskedasticity in asset returns: A new approach. Econometrica 59: 347-70. [CrossRef]

Nguyen, Anh Thi Kim, and Loc Dong Truong. 2020. The impact of index future introduction on spot market returns and trading volume: Evidence from Ho Chi Minh Stock Exchange. Journal of Asian Finance, Economics and Business 7: 51-59. [CrossRef]

Park, Chang-Gyun, and Kyung-Mook Lim. 2003. Expiration day effects in Korean stock market: Wag the dog? KDI Journal of Economic Policy 25: 137-70.

Sadath, Anver, and Bandi Kamaiah. 2011. Expiration effects of stock futures on the price and volume of underlying stocks: Evidence from India. The IUP Journal of Applied Economics 10: 25-38. 
Samineni, Ravi Kumar, Raja BabuPuppala, Ramesh Muthangi, and Syamsundar Kulapathi. 2020. Expiration-day effects on index futures: Evidence from Indian market. The Journal of Asian Finance, Economics, and Business 7: 95-100. [CrossRef]

Spyrou, Spyros I. 2005. Index futures trading and spot price volatility: Evidence from an emerging market. Journal of Emerging Market Finance 4: 151-67. [CrossRef]

Stoll, Hans R., and Robert E. Whaley. 1987. Program trading and expiration-day effects. Financial Analysts Journal 43: 16-28. [CrossRef]

Stoll, Hans R., and Robert E. Whaley. 1997. Expiration-day effects of all ordinaries share price index futures: Empirical evidence and alternative settlement procedures. Australian Journal of Management 22: 139-74. [CrossRef]

Truong, Loc Dong. 2012. Day-of-the-week effect on stock returns and volatility: The case of Ho Chi Minh Stock Exchange, Vietnam. Asian Journal of Research Management 2: 711-21.

Truong, Loc Dong, and H. Swint Friday. 2021. The impact of the introduction of index futures on the daily returns anomaly in the Ho Chi Minh Stock Exchange. International Journal of Financial Studies 9: 43. [CrossRef]

$\mathrm{Xu}$, Caihong. 2014. Expiration-day effects of stock and index futures and options in Sweden: The return of the witches. Journal of Futures Markets 34: 868-82. [CrossRef] 